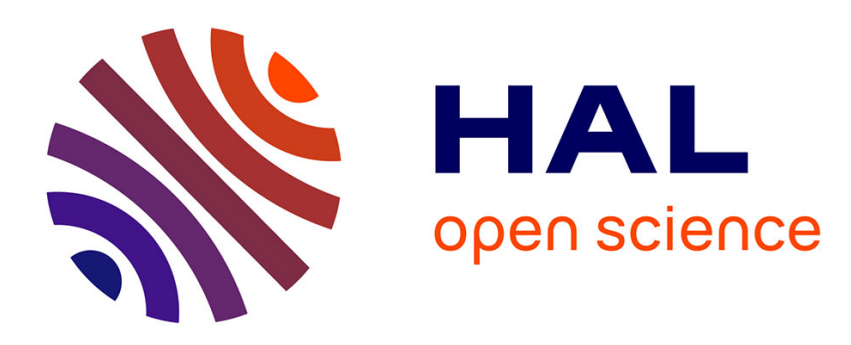

\title{
Critical behaviour of electric failure thresholds in percolation
}

\author{
E. Guyon, S. Roux, D.J. Bergman
}

\section{To cite this version:}

E. Guyon, S. Roux, D.J. Bergman. Critical behaviour of electric failure thresholds in percolation. Journal de Physique, 1987, 48 (6), pp.903-904. 10.1051/jphys:01987004806090300 . jpa-00210518

\section{HAL Id: jpa-00210518 https://hal.science/jpa-00210518}

Submitted on 1 Jan 1987

HAL is a multi-disciplinary open access archive for the deposit and dissemination of scientific research documents, whether they are published or not. The documents may come from teaching and research institutions in France or abroad, or from public or private research centers.
L'archive ouverte pluridisciplinaire HAL, est destinée au dépôt et à la diffusion de documents scientifiques de niveau recherche, publiés ou non, émanant des établissements d'enseignement et de recherche français ou étrangers, des laboratoires publics ou privés. 
Classification

Physics Abstracts

$05.50-62.20 \mathrm{M}-64.60 \mathrm{~A}$

\title{
CRITICAL BEHAVIOUR OF ELECTRIC FAILURE THRESHOLDS IN PERCOLATION
}

\author{
E. Guyon, S. Roux and D.J. Bergman ${ }^{+}$ \\ Laboratoire d'Hydrodynamique et Mécanique Physique, UA CNRS 857, ESPCI \\ 10, rue Vauquelin, 75231 Paris Cedex 05, France \\ + The Raymond and Beverly Sackler Faculty of Exact Sciences, School of Physics and \\ Astronomy, Tel Aviv University, Tel-Aviv, 699978 Israel
}

(Reçu le 28 janvier 1987, accepté sous forme définitive le 10 avril 1987)

\begin{abstract}
Résumé.- Dans ce commentaire, nous montrons que le comportement critique en percolation d'un réseau aléatoire dont les éléments individuels ont une limite finie de résistance à la rupture est différent pour le problème électrique et mécanique. Ceci est dû au fait que seuls les moments et les distorsions angulaires contribuent à la rupture dans le cas mécanique.
\end{abstract}

\begin{abstract}
In this comment we show that the scaling behaviour of the failure threshold of a random lattice whose individual elements have a rupture threshold will be different for the mechanical and electrical problems in percolation conditions. This is due to the fact that only torques and angular distortions are effective in bringing about rupture in the mechanical case.
\end{abstract}

The difference in the critical behaviours of the conductivity and the elastic moduli of random lattices above the percolation threshold has already been emphasized in several theoretical [1-3], numerical [4-6], and experimental [7-8] works. The differences basically stem from the fact that, whereas the conductivity properties come from a scalar (potential) problem, the elasticity comes from a vector (displacement) problem.

In this comment, we stress that this difference also introduces a difference in critical behaviour between the electrical and mechanical rupture properties of these percolation structures. Preliminary studies on this, or related, problem have recently been reported [9].

Using the well-known node, link and blob picture of the percolation backbone [10-13], one can relate the current $i$ flowing into a macro-bond of length (the correlation length), to the current density $j$ imposed on the boundary by :

$$
i \simeq j \xi^{(d-1)}
$$

where $d$ is the space-dimension. In a random fuse percolation problem [14] it has been assumed that rupture will occur in any bond of a random lattice if the current flowing through it reaches a threshold value $i_{\mathrm{c}}$. Therefore as there exist singly connected bonds in the macro-bonds, rupture will develop macroscopically when the current in an individual bond reaches its critical value $i=i_{\mathrm{c}}$, or

$$
j \simeq i_{c} \xi^{(1-d)}
$$

Within the node-link-blob model, we cannot distinguish between the onset of failure (first broken bond) and the macroscopic failure. The density of current for failure, $j_{\mathrm{f}}$, will scale as

$$
j_{\mathrm{f}} \sim\left(p-p_{\mathrm{c}}\right)^{\nu(d-1)}
$$

as suggested in the work of reference [14]. A similar scaling relation was proposed for the critical current in a superconductor random lattice [15].

Similarly, in the elastic problem if a stress $\sigma$ is applied at the boundary the force $f$ that will be carried in a macro-link is

$$
f \simeq \sigma \xi^{(d-1)}
$$

In addition, the torques $m$ that will be transmitted in the macro-link will be such that :

$$
m \sim f \xi \sim \sigma \xi^{d}
$$


Near threshold, the effect of torques dominates $[2,3]$ : if we introduce, for any bond, two failure criteria $F=F_{\text {c }}$ (for forces) and $M=M_{\mathrm{c}}$ (for torques), the latter one will be the only limiting factor for sufficiently large $\xi$, that is sufficiently close to $p_{\mathrm{c}}$. The failure stress, $\sigma_{\mathrm{g}}$, will thus be given by :

$$
m=M_{\mathrm{c}}
$$

or

$$
\sigma_{\mathrm{f}} \sim M_{\mathrm{c}} \xi^{-d} \sim\left(p-p_{\mathrm{c}}\right)^{T_{\mathrm{g}}} \quad \text { with } T_{\mathrm{g}}=\nu d
$$

The exponent $\nu d$ can be seen to coincide with the expression given previously by one of us [16] in a bound approach. More specifically, it was predicted in that work that :

$$
\xi^{((1-T) / \nu)}<\sigma_{f}<\xi^{(z-T / \nu)}
$$

where $T$ is the critical exponent of elasticity.

In this double inequality, the lower value is related to the effect of the divergence of the total length of singly connected bonds on a macro-bond as $\xi^{1 / \nu}$ whereas the upper one is related to the effect of the shortest path which diverges as $\xi^{z}$.

At this level, we can make use of bounds for $T$ which arise from the same effects : the lower bound takes into account only the singly connected bonds and :

$$
T>1+\nu d
$$

whereas the upper bounds come from the shortest path approximation

$$
T<\nu(d+z)
$$

Combining these two inequalities independently, we find, as in reference [16] :

$$
\nu d+1-z<T_{\mathrm{f}}<\nu d+z-1
$$

However, if instead of considering the bounds for $T$ and $T_{f}$ independently, we consider the values of the bounds for $T$ and $T_{\mathrm{f}}$ within the same approximation (either singly connected bonds or shortest parth), the two bounds for the failure critical exponent collapse to the same value, $\nu d$, given above. Explicitly, in the singly connected bonds approximation :

$$
T \sim(T-1) \sim(1+\nu d-1)=\nu d
$$

and in the shortest part approach, we again get :

$$
T_{\mathrm{f}} \sim(T-\nu z) \sim(\nu(d+z)-\nu z)=\nu d
$$

The reason why these two methods give the same result lies in the fact that, actually, there was no need to estimate the elasticity of any element in order to get the rupture exponent. It is sufficient to look carefully at the correspondance between the macroscopic scale $(>>\xi)$ and microscopic one $(<\xi)$. Then the failure criterion being given at the local (microscopic) scale, we can just translate it geometrically to the macroscopic scale using the node-link and blob picture.

\section{Reference}

[1] Kantor Y., Bergman D.J., Phys. Rev. Lett. 53 (1984) 511.

[2] Kantor Y., Webman I., Phys. Rev. Lett. 52 (1984) 1891.

[3] Roux S., J. Phys. A19 (1986) L351.

[4] Feng S., Sen P.N., Phys. Rev. 52 (1984) 216.

[5] Bergman D.J., Phys. Rev. B31 (1985) 1696.

[6] Zabolitzky J.G., BergmaN D.J., STAUfFeR D., J. Stat. Phys. 44 (1986) 211.

[7] Deptuck D., HarRison J.P., ZaWAdsky P., Phys. Rev. Lett. 54 (1985) 913.

[8] Benguigui L., Phys. Rev. Lett. 53 (1984) 2028.

[9] Benguigui L., Flux, Flow, Fragmentation, Ann. Isr. Soc. 8 (1986) 288 ; SIERDZKI K., LI R., Phys. Rev. Lett. 56 (1986) 2509, DE ARCANGELIS L., REDNER S., HERMANN H.J., J. Physique Lett. 46 (1985) L-585, ChaKrabarTy B.K., CHOWDURY D., Stauffer D., Z. Physik 62 (1986) 343.

[10] Skal A., ShKlovski B., Sov. Phys. Semicond. 8 (1986) 1029.

[11] De Gennes P.G., J. Physique Lett. 37 (1976) L-1.

[12] Stanley H.E., J. Phys. A10 (1977) L211.

[13] Coniglio A. in Disordered Systems and Localization, vol 149 of Lecture Notes in Physics, eds. Castellani C., Di Castro C. and Peliti L. (Springer, Berlin, 1981).

[14] Gilabert A., Vanneste C., Sornette D., GUYON E., to appear in J. Physique.

[15] Deutscher G. Les Houches lectures (1986).

[16] Bergman D.J. Flux, Flow, Fragmentation, Ann. Isr. Soc. 8 (1986) 266. 